\title{
Similar Diagnostic Accuracy and Reproducibility of BI- RADS 4 and 5 Lesions in Radial and Meander-Like Breast Ultrasound
}

\author{
Brasier-Lutz P1, Jäggi-Wickes C $C^{1}$, Schaedelin S , \\ Burian $\mathbf{R}^{1}$, Schoenenberger $\mathbf{C A}^{3,4}$ and Zanetti- \\ Dällenbach $\mathbf{R}^{4 *}$ \\ ${ }^{1}$ Department of Obstetrics and Gynecology, University \\ Hospital Basel, Switzerland \\ ${ }^{2}$ Department of Clinical Research, Statistics and Data \\ Management, University Basel, Switzerland \\ ${ }^{3}$ Department of Chemistry, University Basel, Switzerland \\ ${ }^{4}$ Gynecology/ Gynecologic Oncology, St. Claraspital Basel, \\ Switzerland \\ *Correspondling author: Zanetti-Dällenbach R, \\ Gynecology/ Gynecologic Oncology, St. Claraspital Basel, \\ Kleinriehenstrasse 30, 4085 Basel, Switzerland
}

Received: December 22, 2020; Accepted: January 12, 2021; Published: J anuary 19, 2021

\begin{abstract}
Breast ultrasound is crucial in the diagnostics of breast cancer. While meander-like Ultrasound ( $\mathrm{m}-\mathrm{US}$ ) is most commonly used, radial Ultrasound ( $r$ US) is emerging as suitable alternative. Breast lesions category BI-RADS 4 and 5 are suspicious and highly suggestive of malignancy, respectively, and mandate breast biopsy. We compare $\mathrm{m}$-US and $\mathrm{r}$-US in real-time with regard to diagnostic accuracy, examination time and the agreement in location, size and final BIRADS classification of BI-RADS 4 and 5 lesions. Out of 1948 dual examinations ( $\mathrm{m}$-US and r-US), 57 lesions were classified as BI-RADS 4 or 5 either by $r$-US or m-US or by both scanning methods. For breast lesions category BI-RADS 4 or 5 , sensitivity (both scan methods $94.1 \%$ ), specificity (m-US $21.7 \%$, r-US $39.1 \%$ ), cancers missed rate (both $5.9 \%$ ), accuracy (m-US $64.9 \%$, r-US $71.9 \%$ ), positive predictive value (m-US 64.0\%, r-US 69.6\%) and negative predictive value (both $100 \%$ ) were similar. In m-US, the malignancy rate for category BI-RADS 5 was $93.8 \%$ versus for $50.0 \%$ for BI-RADS 4 whereas in r-US, malignancy rates were $88.2 \%$ and $58.6 \%$ for category BI-RADS 5 and 4 , respectively. The examination was significantly shorter $(p<0.01)$ for $r$-US $(13.6$ minutes) compared to $m$-US (27.8 minutes). Our results support radial ultrasound as an alternative to meander-like ultrasound in breast lesions category BI-RADS 4 and 5 where patients benefit from a significantly shorter examination time.
\end{abstract}

Keywords: Agreement, BI-RADS 4 and 5, Diagnostic accuracy, Ductosonography, Examination time, Radial breast ultrasound

\section{Abbreviations}

US: Ultrasound; m-US: meander-like Ultrasound; r-US: radial Ultrasound; CI: Confidence Interval; ICC: Intraclass-Correlation; PPV: Positive Predictive Value; NPV: Negative Predictive Value

\section{Introduction}

Breast Ultrasound is a well-established and essential tool in the evaluation of breast lesions in daily clinical practice. The characterization and ultrasound classification of breast lesions follows the standardized recommendation of the BI-RADS Atlas [1]. The latter also provides clear recommendations on how to proceed for each BI-RADS category. Breast lesions category BI-RADS 4 are suspicious of malignancy and breast lesions category BI-RADS 5 are highly suggestive of malignancy. While in breast lesions category 4 and 5 histologic clarification by breast biopsy is indicated, a short term follow-up is proposed for BI-RADS 3 breast lesions (probably benign).

Most clinicians perform breast Ultrasound (US) by moving the probe in a meander-like pattern in two orthogonal planes. Even though Rosensweig introduced [2] radial ultrasound, also called ductosonography, already in 1982, it is seldom used as the sole ultrasound method in daily clinical practice. Radial Ultrasound ( $\mathrm{r}$ US) is usually performed as an adjunct to meander-like Ultrasound (m-US) in case of nipple discharge [3,4] or ductal abnormalities [5].
However, only in a few studies, radial scanning was performed [6-10]. A recent comparison of $\mathrm{r}$-US and $\mathrm{m}$-US showed that the diagnostic accuracy of the two scanning procedures is similar [11]. We and others have proposed r-US to be a viable alternative to m-US [12-14].

Real time scanning provides the opportunity for careful and thorough evaluation of breast lesions and permits detailed lesion analysis during the examination, which is a major advantage over retrospective analysis of static images on a screen [14]. Moreover, true comparison of lesion location, lesion size, examination time and most of all, the number of lesions missed by one examinator is only feasible by real-time scanning and assessment by different examinators.

Here, we compare for the first time the diagnostic accuracy, the examination time and the agreement in lesion localization, lesion size and final BI-RADS classification of real-time meander-like US and real-time radial US in regard to breast lesions suspicious and highly suggestive of malignancy mandating breast biopsy, i.e. BI-RADS category 4 and 5.

\section{Materials and Methods}

The single center study (Department of Obstetrics and Gynecology, University Hospital Basel, Switzerland) was approved by the local ethical committee and conducted from August 2011 to August 2014. Women from an unselected, consecutive, mixed collective who participated in this study signed an informed consent
Austin J Womens Health - Volume 8 Issue 1 - 2021

Submit your Manuscript | www.austinpublishinggroup.com

Zanetti-Dällenbach et al. (C) All rights are reserved
Citation: Brasier-Lutz P, Jäggi-Wickes C, Schaedelin S, Burian R, Schoenenberger CA and Zanetti-Dällenbach R. Similar Diagnostic Accuracy and Reproducibility of BI-RADS 4 and 5 Lesions in Radial and Meander-Like Breast Ultrasound. Austin J Womens Health. 2021; 8(1): 1046. 
form. Symptomatic women with breast pain or palpable breast lumps, asymptomatic women with increased risk for breast cancer or with dense breast tissue, and women with a personal history of breast cancer constitute the study group. An age younger than 18 years, a scheduled breast biopsy and male gender were exclusion criteria.

The examiners collected all demographic data including data on personal and family history, and performed a physical breast examination. Subsequently, each woman received a bilateral $r$-US and $\mathrm{m}$-US in random order by two different examiners. Both examiners had access to the clinical and mammographic findings but not to the corresponding US assessment of the other examiner.

All examiners received a yearly training in breast US. In addition, the research fellow who performed all $r$-US underwent a theoretical and practical didactic training in $\mathrm{r}$-US at the beginning of the study. M-US was carried out by experts or beginners under the supervision of an expert, as it is common in teaching hospitals.

Both US examinations ( $\mathrm{m}$-US and $\mathrm{r}$-US) were performed with an ultrasound equipment of the same type (EUB-7500 V 16-53 Step 3.5, Hitachi Medical Systems Europe Holding AG, Zug, Switzerland). For m-US, a 50mm wideband, high frequency (13-5 MHz) linear transducer (EUP-L74M) was employed while r-US was carried out using a $92 \mathrm{~mm}$ wideband (10-5 MHz) linear transducer (EUP-L53L) with a water standoff (a water-filled latex cover) according to the manufacturer's instructions. Both transducers had a center frequency of $7.5 \mathrm{MHz}$.

The duration of the US-examination was determined based on the timestamp on images taken at the beginning and at the end of the US-examination.

US-examinations were carried out as described in Jäggi et al. [11]. In brief, the women lied in an oblique supine position with her ipsilateral arm raised behind her head to flatten the breast tissue. For $\mathrm{r}$-US, the examiner moved the transducer first clockwise around the mammilla in a radial and then in an anti-radial fashion, followed by a radial and anti-radial sweep of the upper outer quadrant to examine the axillary tail. In m-US, the transducer was moved in a meanderlike pattern in vertical and transverse direction. Both $\mathrm{r}$-US and m-US routinely included scanning of the axilla.

For both scanning methods, we measured the dimensions of each sonographic lesion on recordings in two orthogonal planes [11]. For each lesion the morphologic features were described and the lesions classified according to the BI-RADS Atlas [15] by the examiners. The location of each lesion was recorded according to the clock-face. In $\mathrm{r}$-US, the mammilla is visualized as the rotation point which allowed for measuring the distance between lesion and nipple due to the wide probe whereas in m-US, the nipple-lesion distance was estimated. The shortest distance between lesion and skin was recorded in both US methods.

Breast lesions classified as BI-RADS 4 or 5 were biopsied for histological analysis.

Size, location, morphologic characteristics of the lesion and their final BI-RADS classification were electronically saved in the patient record (ViewPoint ${ }^{\oplus}$, Version 5: GE Healthcare GmbH, Munich, Germany).
All data on patient and lesion characteristics extracted from the electronic patient records were entered into $\mathrm{R}$ ( $\mathrm{R}$ Core Team (2019). R: A language and environment for statistical computing. R Foundation for Statistical Computing, Vienna, Austria. URL https:// www.R-project.org) for further analysis.

\section{Statistical methods}

Patient and lesion characteristics were summarized. Categorical data are presented as frequencies and percentages. For continuous variables, mean and standard deviation as well as range are given.

Examination time was compared between $\mathrm{m}$-US and $\mathrm{r}$-US using a Wilcoxon signed rank test with continuity correction. For the assessment of diagnostic accuracy, histological results served as gold standard. Where lesions were missed by r-US or by m-US, the lesions were considered normal breast tissue and were interpreted accordingly for statistical analysis. For both methods, the sensitivity, specificity, and accuracy were calculated with 95\% Confidence Intervals (CIs). The CIs were estimated according to Blaker. P-values were calculated using the exact McNemar's test. Positive and negative predictive values were calculated together with corresponding $95 \%$ $\mathrm{CIs}$, and the respective p-values calculated. The negative predictive value was calculated either including or excluding missed cancers. Only lesions described by both methods were compared and used for p-value calculation.

For BI-RADS 4 and 5 breast lesions, the proportion of true positive, false negative, and cancers missed by one of the scan methods were calculated for malignant lesions. Correspondingly, the proportion of true negative and false positive, and the proportion of benign lesions not revealed were calculated for benign lesions. For data comparison between the two scan methods, an exact McNemar's test was used.

Lesions from the same subject were considered independent. All analyses were performed by $R$. No correcting for multiple testing was performed.

In categorical variables, agreement between the two scanning procedures was quantified using $\kappa$-values with quadratic weights. However, for the endpoint "clock-face location" the cyclicity was taken into account by choosing weights according to the distance on the clock rather than absolute timepoints, meaning that the distance between " 0 " and " 1 " and between " 11 " and " 0 " is 1 hour in both cases.

Weighted $\kappa$-values were interpreted as suggested by Landis: $\leq 0.20$ poor agreement, 0.21-0.40 fair agreement, 0.41-0.60 moderate agreement, 0.61-0.80 substantial agreement, and 0.81-1.00 excellent agreement.

In continuous variables, the agreement was quantified using Intraclass-Correlation (ICC). The ICC is calculated based on analysis of variance. To this end, a mixed model is fitted to the data with scanning procedure and patient as random factors, and a fixed intercept was fitted. The ICC was estimated by dividing the variation related to the patient-to-patient difference by the total variance in the data. Therefore, ICC ranged between 0 and 1 and can be interpreted as the proportion of the variation of the data, which can be attributed to patient-to-patient variability. An ICC of 1 indicates a perfect agreement between $\mathrm{r}$-US and $\mathrm{m}$-US and that all differences 
Table 1: Patient and lesion characteristics.

\begin{tabular}{|c|c|c|c|}
\hline Patient characteristics & \multicolumn{1}{|c|}{$\begin{array}{c}\text { Lesion } \\
\text { characteristics }\end{array}$} & \\
\hline Number of patients & $51(100 \%)$ & Number of lesions & $57(100 \%)$ \\
\hline Positive personal history & $2(3.9 \%)$ & Benign lesions & $23(40.4 \%)$ \\
\hline Positive family history & $17(33.3 \%)$ & Fibroadenoma & 5 \\
\hline Breast cancer & 16 & Fibrosis/sclerosis & 11 \\
\hline $\begin{array}{c}\text { Breast and ovarian } \\
\text { cancer }\end{array}$ & 1 & Other B2 lesions & 5 \\
\hline $\begin{array}{c}\text { Mean age in years } \\
\text { (min,max) [SD] }\end{array}$ & 56.4 & B3 lesions & 2 \\
\hline & & Malignant lesions & $34(59.6 \%)$ \\
\hline & & Invasive lobular cancer & 3 \\
\hline
\end{tabular}

in the ratings are due to differences in the patients. For the variable "mean volume", the data was cube-root transformed prior to fitting the model since the volume was estimated from the main axes and thus, any errors when measuring these axes were inflated, leading to outliers not acceptable in the mixed model.

ICC-values were interpreted according to Cicchetti: $<0.40$ poor agreement, 0.40-0.59 fair agreement, 0.60-0.74 good agreement, and 0.75-1.00 excellent agreement.

\section{Results}

In this study, we investigated the diagnostic accuracy of both scanning methods for sonographic breast lesions characterized as BI-RADS 4 or 5. Additionally, we analyzed the agreement of m-US and r-US with regard to size, location and morphologic characteristic of each breast lesion and compared the examination time for both scanning methods.

Out of 1984 dual US-examinations (r-US and m-US), 57 lesions from 51 patients were classified as BI-RADS 4 or 5 in either m-US or $\mathrm{r}$-US or in both scanning methods. Corresponding patient and lesion characteristics are presented in Table 1 . The patients were on average 56.4 years (30-86 years) old. The mean age of patients diagnosed with breast cancer was 58.0 years (30-79 years) and 53.8 years ( $30-86$ years) for patients with a benign lesion $(\mathrm{p}=0.07)$. Two $(3.9 \%)$ patients had a positive personal and 17 (33.3\%) patients a positive family history.

Of the breast lesions classified as BI-RADS 4 or 5 in one or both scanning approaches, 27 (47.4\%) were palpable. Breast cancer was diagnosed in $59.6 \%(n=34)$ of the lesions and $40.4 \%(n=23)$ had a benign histology (Table 1).

For BI-RADS 4 or 5 breast lesions both m-US and r-US had a sensitivity of $94.1 \%$. The specificity for $\mathrm{m}$-US was $21.7 \%$ and for $\mathrm{r}$-US $39.1 \%$ (Table 2). Two cancers were missed by r-US but correctly identified by m-US. Two other cancers were missed by $\mathrm{m}$-US but correctly identified by $\mathrm{r}$-US. This corresponds to a cancer missed rate of $5.9 \%$ for either scanning method. Of the 23 lesions with a benign histology, 5 (21.7\%) were correctly classified as BI-RADS 3 in m-US, and $8(34.8 \%)$ lesions in r-US. In m-US 18 (78.3\%) and in r-US 14 (60.9\%) benign lesions were classified as BI-RADS 4 or 5 . One (4.3\%) benign lesion was missed in $\mathrm{r}$-US, but none in $\mathrm{m}$-US. As summarized in Table 2, sensitivity, specificity, accuracy, positive (PPV) and
Table 2: Diagnostic accuracy of m-US and r-US in BI-RADS 4 and 5 breast lesions.

\begin{tabular}{|c|c|c|c|c|c|}
\hline & \multicolumn{2}{|c|}{$\begin{array}{l}\text { Meander-Like } \\
\text { Ultrasound }\end{array}$} & \multicolumn{2}{|c|}{$\begin{array}{l}\text { Radial } \\
\text { Ultrasound }\end{array}$} & \\
\hline & $\mathrm{n}$ & $\%$ & $\mathrm{n}$ & $\%$ & \\
\hline Malignant lesions & 34 & 100 & 34 & 100 & \\
\hline Cancers identified & 32 & 94.1 & 32 & 94.1 & \\
\hline True positive (BI-RADS 4 or 5 ) & 32 & 94.1 & 32 & 94.1 & ns \\
\hline Cancers missed & 2 & 5.9 & 2 & 5.9 & \\
\hline False negative* (BI-RADS 3) & 0 & 0 & 0 & 0 & ns \\
\hline $\begin{array}{c}\text { False negative* (BI-RADS } 3 \text { and } \\
\left.\text { missed cancers }{ }^{\star *}\right)\end{array}$ & 2 & 5.9 & 2 & 5.9 & ns \\
\hline Benign lesions & 23 & 100 & 23 & 100 & \\
\hline Benign lesions identified & 23 & 100 & 22 & 95.7 & ns \\
\hline True negative (BI-RADS 3) & 5 & 21.7 & 8 & 34.8 & ns \\
\hline Benign lesions missed & 0 & 0 & 1 & 4.3 & ns \\
\hline False positive* (BI-RADS 4 or 5 ) & 18 & 78.3 & 14 & 60.9 & ns \\
\hline $\begin{array}{c}\text { False positive }{ }^{*}(\text { BI-RADS } 4 \text { or } 5 \text { and } \\
\left.\text { missed lesions }{ }^{* *}\right)\end{array}$ & 18 & 78.3 & 15 & 65.2 & ns \\
\hline \multicolumn{6}{|l|}{ Diagnostic Accuracy } \\
\hline Sensitivity & & 94.1 & & 94.1 & ns \\
\hline Specificity & & 21.7 & & 39.1 & ns \\
\hline Accuracy & & 64.9 & & 71.9 & ns \\
\hline PPV & & 64.0 & & 69.6 & ns \\
\hline NPV (excluding missed cancers) & & 100.0 & & 100.0 & ns \\
\hline NPV (including missed cancers) & & 71.4 & & 81.8 & ns \\
\hline
\end{tabular}

False negative and false positive were calculated excluding ${ }^{*}$ and including ${ }^{*}$ missed lesions.

PPV: Positive Predictive Value; NPV: Negative Predictive Value; ns: not significant

Negative Predictive Values (NPV) are similar for m-US and r-US.

The malignancy rate for lesions classified as BI-RADS 5 was $93.8 \%$ in $\mathrm{m}$-US and 88.2 for r-US and for lesions classified as BI-RADS 4 $50.0 \%$ for $\mathrm{m}$-US and $58.6 \%$ for r-US (Table 3 ).

The dimensions of each lesion were measured in two orthogonal planes for both scanning methods. The mean maximal diameter and the calculated mean volume for $\mathrm{r}$-US and $\mathrm{m}$-US are listed in Table 4. The ICC values for the mean maximal diameter was 0.55 and for the mean volume 0.43 , indicating fair agreement of these parameters between the two scanning procedures.

The location of each lesion as described by clock-face localization, and its distance to the mammilla and to the skin are presented in Table 4 . The agreement in clock-face localization was excellent $(\kappa=0.89)$ and for the mean distance to the mammilla (ICC 0.63) and to the skin (ICC 0.67) good.

For both US methods, each breast lesion was characterized according to the morphologic criteria described in the BI-RADS Atlas [15] and a BI-RADS category specified by the examiner. For breast lesions characterized as BI-RADS 4 or 5 in $\mathrm{m}$-US or $\mathrm{r}$-US or in both scanning methods, we found fair agreement in lesion orientation and echo pattern, moderate agreement in shape, posterior acoustic features, and tissue composition, and substantial agreement in lesion margin and breast density. The final BI-RADS classification moderately agreed ( $\kappa 0.51)$ for $\mathrm{m}$-US and $\mathrm{r}$-US (Table 5 ). 
Table 3: BI-RADS classification by $\mathrm{m}-\mathrm{US}$ and $\mathrm{r}$-US related to malignant and benign histology.

\begin{tabular}{|c|c|c|c|}
\hline & All lesions & Malignant lesions & Benign lesions \\
\hline & $\mathrm{n}(\%)$ & $\mathrm{n}(\%)$ & $\mathrm{n}(\%)$ \\
\hline & $57(100)$ & $34(59.6)$ & $23(40.4)$ \\
\hline \multicolumn{4}{|l|}{ Meander-like ultrasound } \\
\hline BI-RADS 5 & $16(100)$ & $15(93.8)$ & $1(6.2)$ \\
\hline BI-RADS 4 & $34(100)$ & $17(50.0)$ & $17(50.0)$ \\
\hline BI-RADS 3 & $5(100)$ & - & $5(100.0)$ \\
\hline BI-RADS 2 & - & - & - \\
\hline Missed breast lesions & $2(100)$ & $2(100.0)$ & $0(0.0)$ \\
\hline \multicolumn{4}{|l|}{ Radial ultrasound } \\
\hline BI-RADS 5 & $17(100)$ & $15(88.2)$ & $2(11.8)$ \\
\hline BI-RADS 4 & $29(100)$ & $17(58.6)$ & $12(41.4)$ \\
\hline BI-RADS 3 & $7(100)$ & - & $7(100)$ \\
\hline BI-RADS 2 & $1(100)$ & - & $1(100)$ \\
\hline Missed breast lesions & $3(100)$ & $2(66.7)$ & $1(33.3)$ \\
\hline
\end{tabular}

Table 4: Agreement of size and location of BI-RADS 4 and 5 breast lesions.

\begin{tabular}{|c|c|c|c|c|c|}
\hline & Radial US & Meander-like US & ICC & Weighted kappa & Agreement \\
\hline \multicolumn{6}{|l|}{ Size } \\
\hline $\begin{array}{l}\text { Mean max. lesion diameter (mm) } \\
(\min , \max )[S D]\end{array}$ & $\begin{array}{c}13.7 \\
(3.5,42.7)[9.3]\end{array}$ & $\begin{array}{c}14.4 \\
(5.00,49.1)[9.3]\end{array}$ & 0.55 & & Fair \\
\hline $\begin{array}{l}\text { Mean volume }(\mathrm{ml}) \\
(\min , \max )[\mathrm{SD}]\end{array}$ & $\begin{array}{c}1.4 \\
(0.02,14.6)[2.7]\end{array}$ & $\begin{array}{c}1.7 \\
(0.02,20.2)[3.7]\end{array}$ & 0.43 & & Fair \\
\hline \multicolumn{6}{|l|}{ Location } \\
\hline $\begin{array}{l}\text { Mean distance to mammilla }(\mathrm{mm})^{\star} \\
(\min , \max )[\mathrm{SD}]\end{array}$ & $\begin{array}{c}28.0 \\
(0.0,86.0)[21.0]\end{array}$ & $\begin{array}{c}35.2 \\
(0.0,100.0)[23.5]\end{array}$ & 0.63 & & Good \\
\hline $\begin{array}{l}\text { Mean distance to skin }(\mathrm{mm}) \\
(\min , \max )[\mathrm{SD}]\end{array}$ & $\begin{array}{c}9.2 \\
(2.0,23.0)[5.1]\end{array}$ & $\begin{array}{c}6.9 \\
(2.0,17.0)[3.6]\end{array}$ & 0.67 & & Good \\
\hline
\end{tabular}

'The wide probe and the mammilla as rotation point enabled the measurement of the distance from the lesion to the mammilla in $\mathrm{r}$-US which was estimated in $\mathrm{m}$-US.

Table 5: Agreement between m-US and r-US with regard to morphologic description of BI-RADS 4 and 5 breast lesions.

\begin{tabular}{|c|c|c|}
\hline & Weighted kappa & Agreement \\
\hline Shape & 0.44 & Moderate \\
\hline Orientation & 0.24 & Fair \\
\hline Margin & 0.64 & Substantial \\
\hline Echo pattern & 0.30 & Fair \\
\hline Posterior acoustic features & 0.41 & Moderate \\
\hline Tissue composition & 0.48 & Moderate \\
\hline Breast density* & 0.76 & Substantial \\
\hline Final BI-RADS classification & 0.51 & Moderate \\
\hline
\end{tabular}

According to Madjar et al. [25].

The duration of the examination was timed and revealed a significantly shorter mean examination time for r-US (13.6 minutes) compared to m-US (27.8 minutes) (Table 6).

\section{Discussion}

The data of this study show a similar diagnostic accuracy of Table 6: Examination time for m-US and r-US
$\mathrm{m}$-US and r-US for lesions BI-RADS category 4 and 5 . There was good agreement in lesion localization, fair agreement in lesion size and moderate agreement in final BI-RADS classification for the two scanning methods. However, examination time was significantly shorter in $\mathrm{r}$-US compared to m-US.

Studies on m-US revealed malignancy rates for BI-RADS 5 lesions ranging from $57.1 \%$ [16] to $97.5 \%$ [17] and for BI-RADS 4 lesions from $8.6 \%$ [18] to $47.8 \%$ [19]. We found malignancy rates of 93.8\% in m-US and 88.2 for r-US for BI-RADS 5 lesions, which for both scanning procedures is in the upper range of malignancy rates reported for m-US. In BI-RADS 4 lesions, our malignancy rates were $50.0 \%$ for $\mathrm{m}$-US and $58.6 \%$ for $\mathrm{r}$-US, each of which is higher than those reported in the literature.

For BI-RADS 4 and 5 lesions, we found the same sensitivity for m-US and r-US of $94.1 \%$, and a specificity of $21.7 \%$ for m-US and $39.1 \%$ for $r$-US. Our findings are in line with Lee et al. [20] who reported a sensitivity of $98 \%$ and a specificity of $33 \%$ for m-US.

The PPV and NPV is $64.0 \%$ and $100.0 \%$ for $\mathrm{m}$-US, respectively,

\begin{tabular}{|c|c|c|c|}
\hline & Meander-like Ultrasound & Radial Ultrasound & p-Value \\
\hline Mean examination duration (minutes) & 27.8 & 13.6 & $<0.01$ \\
\hline$(\min , \max )[\mathrm{SD}]$ & $(4.7 ; 74.0)[17.3]$ & $(3.9 ; 38.5)[6.3]$ \\
\hline
\end{tabular}


and $69.6 \%$ and $100.0 \%$ for r-US. Similar values of $65 \%$ for PPV have been reported for BI-RADS 4 and 5 lesions [19].

In our study, two breast cancers were missed by m-US and two different breast cancers by $r$-US. Both malignancies missed by one method were identified by the other method which results in a cancer missed rate of $5.9 \%$. Each method detected $94.1 \%$ malignant lesions. For m-US, Berg et al. [21] reported that individual investigators detected between $49 \%$ and $66 \%$ of breast lesions, independent of BIRADS classification.

The agreement of BI-RADS classification between $\mathrm{m}$-US and $\mathrm{r}$-US was moderate ( $\kappa$ 0.51). Similarly, moderate ( $\kappa 0.48)$ agreement for $\mathrm{m}$-US was found in another study also reporting real time assessment [21]. Studies on retrospective evaluation of static m-US images revealed moderate ( $\kappa 0.45-0.56$ ) [22,23] to substantial ( $\kappa 0.67-0.68)$ $[23,24]$ agreement.

The agreement in regard to the morphologic description ranged from fair to substantial. We are not aware of any other study investigating the agreement of morphologic features in BIRADS category 4 and 5 breast lesions.

With an average examination time of 13.6 minutes, $r$-US in BIRADS 4 and 5 lesions was significantly $(<0.01)$ shorter compared to m-US (average examination time 27.8 minutes). We consider the wider probe used in $\mathrm{r}$-US the main reason for the shorter examination time. To the best of our knowledge, data specifically addressing the examination times in breast lesions category 4 and 5 have not yet been published

The study design did not allow for the same examiner performing $\mathrm{m}$-US and r-US which might be seen as a limitation. However, knowing the result of the initial US examination would have biased the second US examination. Furthermore, the individual experience of the examiner possibly had an impact on the examination time. However, US examinations performed by inexperienced examiners supervised by experts reflect a common situation in a teaching hospital. Most studies on agreement found in the literature are performed on retrospective analysis of static images. The main advantage of our study however, is that it was carried out in real time, i.e., two examiners evaluated the same lesions with the same type of US equipment.

\section{Conclusion}

In regard to breast lesions classified as BI-RADS 4 and 5, which always mandate a histologic clarification, radial ultrasound is a valuable alternative to meander-like ultrasound. The diagnostic accuracy of the two scanning methods is similar. However, the examination time is significantly shorter in radial ultrasound which is beneficial for patients, health care providers and institutions.

\section{Acknowledgment}

We thank Dr. Dominique Amy (Aix en Provence, France) for his dedicated teaching of radial breast ultrasound.

The study was funded by the Krebsliga beider Basel, Switzerland.

\section{References}

1. Mendelson EB, Böhm-Vélez M, Berg WA. ACR BI-RADS ${ }^{\circ}$ Ultrasound in ACR BI-RADS Atlas ${ }^{\circledR}$, Breast Imaging Reporting and Data System. $5^{\text {th }}$ edition. 2013.

2. Rosensweig R, Foy PM, Cole-Beuglet C, Kurtz AB, Goldberg BB. Radial scanning of the breast: an alternative to the standard ultrasound technique. J Clin Ultrasound. 1982; 10: 199-201.

3. Kim WH, Chang JM, Moon WK, Cho N, Yi A, Koo HR, et al. Intraductal mass on breast ultrasound: final outcomes and predictors of malignancy. AJR Am J Roentgenol. 2013; 200: 932-937.

4. Rissanen $T$, Reinikainen $H$, Apaja-Sarkkinen $M$. Breast sonography in localizing the cause of nipple discharge: comparison with galactography in 52 patients. J Ultrasound Med. 2007; 26: 1031-1039.

5. Ballesio L, Maggi C, Savelli S, Angeletti M, Rabuffi P, Manganaro L, et al. Adjunctive diagnostic value of ultrasonography evaluation in patients with suspected ductal breast disease. Radiol Med. 2007; 112: 354-365.

6. Gheonea IA, Donoiu L, Camen D, Popescu FC, Bondari S. Sonoelastography of breast lesions: a prospective study of 215 cases with histopathological correlation. Rom J Morphol Embryol. 2011; 52: 1209-1214.

7. Gheonea IA, Stoica Z, Bondari S. Differential diagnosis of breast lesions using ultrasound elastography. Indian J Radiol Imaging. 2011; 21: 301-305.

8. Hooley RJ, Greenberg KL, Stackhouse RM, Geisel JL, Butler RS, Philpotts LE. Screening US in patients with mammographically dense breasts: initial experience with Connecticut Public Act 09-41. Radiology. 2012; 265: 59-69.

9. Wojcinski S, Cassel M, Farrokh A, Soliman AA, Hille U, Schmidt W, et al. Variations in the Elasticity of Breast Tissue During the Menstrual Cycle Determined by Real-time Sonoelastography. J Ultrasound Med. 2012; 31: 63-72.

10. Ebner L, Bonel HM, Huber A, Ross S, Christe A. Diagnostic Performance and Additional Value of Elastosonography in Focal Breast Lesions: Statistical Correlation between Size-Dependant Strain Index Measurements, Multimodality-BI-RADS Score, and Histopathology in a Clinical Routine Setting. ISRN Radiol. 2014; 396368.

11. Jaggi-Wickes $C$, Brasier-Lutz $P$, Schaedelin S, Burian R, Schoenenberger CA, Zanetti-Dallenbach R. Comparison of radial and meander-like breast ultrasound with respect to diagnostic accuracy and examination time. Arch Gynecol Obstet. 2020; 301: 1533-1541.

12. Stavros AT. Breast Ultasound. Philadelphia, PA 19106 USA: Lippincott Williams \& Wilkins. 2004.

13. Madjar $H$, Rickard M, Jellins J, Otto R. IBUS guidelines for the ultrasonic examination of the breast. IBUS International Faculty. International Breast Ultrasound School. Eur J Ultrasound. 1999; 9: 99-102.

14. Hooley RJ, Scoutt LM, Philpotts LE. Breast ultrasonography: state of the art. Radiology. 2013; 268: 642-659.

15. Mendelson EBJ, Berg W, Merritt C, Rubin E. ACR BI-RADS ${ }^{\circ}$ Ultrasound in: ACR BI-RADS Atlas ${ }^{\circledR}$, Breast Imaging Reporting and Data System. $4^{\text {th }}$ ed2003.

16. Kim SJ, Ko EY, Shin JH, Kang SS, Mun SH, Han BK, et al. Application of sonographic BI-RADS to synchronous breast nodules detected in patients with breast cancer. AJR Am J Roentgenol. 2008; 191: 653-658.

17. Destrempes F, Trop I, Allard L, Chayer B, Garcia-Duitama J, El Khoury M, et al. Added Value of Quantitative Ultrasound and Machine Learning in BIRADS 4-5 Assessment of Solid Breast Lesions. Ultrasound Med Biol. 2020; 46: 436-444.

18. Lehman CD, Lee Cl, Loving VA, Portillo MS, Peacock S, DeMartini WB. Accuracy and value of breast ultrasound for primary imaging evaluation of symptomatic women 30-39 years of age. AJR Am J Roentgenol. 2012; 199: 1169-1177.

19. Hille $H$, Vetter M, Hackeloer BJ. The accuracy of BI-RADS classification of breast ultrasound as a first-line imaging method. Ultraschall Med. 2012; 33: 160-163.

20. Lee HJ, Kim EK, Kim MJ, Youk JH, Lee JY, Kang DR, et al. Observer variability of Breast Imaging Reporting and Data System (BI-RADS) for breast ultrasound. Eur J Radiol. 2008; 65: 293-298. 
21. Berg WA, Blume JD, Cormack JB, Mendelson EB. Operator dependence of physician-performed whole-breast US: lesion detection and characterization. Radiology. 2006; 241: 355-365.

22. Lazarus E, Mainiero MB, Schepps B, Koelliker SL, Livingston LS. BI-RADS lexicon for US and mammography: interobserver variability and positive predictive value. Radiology. 2006; 239: 385-391

23. Zou X, Wang J, Lan X, Lin Q, Han F, Liu L, et al. Assessment of Diagnostic Accuracy and Efficiency of Categories 4 and 5 of the Second Edition of the BI-RADS Ultrasound Lexicon in Diagnosing Breast Lesions. Ultrasound Med Biol. 2016; 42: 2065-2071.
24. Berg WA, Blume JD, Cormack JB, Mendelson EB. Training the ACRIN 6666 Investigators and effects of feedback on breast ultrasound interpretive performance and agreement in BI-RADS ultrasound feature analysis. AJR Am J Roentgenol. 2012; 199: 224-235.

25. Madjar H, Ohlinger R, Mundinger A, Watermann D, Frenz JP, Bader W, et al. [BI-RADS-analogue DEGUM criteria for findings in breast ultrasound-consensus of the DEGUM Committee on Breast Ultrasound]. Ultraschall Med. 2006; 27: 374-379. 